\title{
INFLUENCE OF CATIONIC AND ANIONIC POLYMERS ON STRENGTH AND SWELL BEHAVIOR OF EXPANSIVE SOIL
}

\author{
Prashanta Poudel $^{1, \bowtie}$ and S. Srividhya ${ }^{2}$ \\ ${ }^{1}$ Department of Civil Engineering, SRMIST, Kattankulathur-603203, India \\ ${ }^{2}$ Department of Civil Engineering, SRMIST, Kattankulathur-603203, India \\ ${ }^{\square}$ Corresponding Author: prashantgraduate@gmail.com
}

\begin{abstract}
This research aims to study the use of cationic (polyvinyl acetate, PVA) and anionic (polyacrylamide, PAM) polymers on the improvement of strength and swell behaviour of expansive soils. All the prepared samples were tested and results were analysed to visualize the effectiveness of admixtures. The use of both polymers showed improvement in the unconfined compressive strength of expansive soil. One dimensional oedometric swell tests were conducted for the optimum content of polymer producing the highest UCS value and one another proportion of polymer to investigate the swell potential and swelling pressure of polymer treated soil. The changes in the microstructure of the treated soil were analysed through SEM imaging.
\end{abstract}

Keywords: Polymer Stabilization, Non-traditional Stabilizers, Soil Improvement, Oedometric Swell Test, SEM Imaging

RASĀYAN J. Chem., Vol. 14, No.2, 2021

\section{INTRODUCTION}

The major problem with normal clayey soil is of long-term settlement whereas some clayey soils are having very fine grain size, high specific surface area and high cation exchange capacity causing the major problem of swell and shrinkage. These later types of clayey soils containing montmorillonite as major mineral content are called expansive soils which cause a huge amount of destruction to structures like buildings, roads, canals embankments etc. Foundations of lightweight structures built on such soils are considered extremely vulnerable to damage because of shrink-swell behavior. These phenomena are caused by the reduction and increase in the moisture content of the soils, which occur seasonally. This effect becomes more prominently worse during dry and rainy seasons. This shrink-swell behavior of expansive soils can lead to damages such as cracks in the exterior walls and at windows and doors corners, differential settlement and deformation. There are reports of plenty of structural damage cases due to construction on expansive soils, especially for water and irrigation structures due to pore water seeping through embankments constructed over expansive soil layers. These expansive soils are very stiff when dry but lose their strength when it's exposure to water is prolonged. The pavements experience settlement, undulations, cracks and unevenness when built on expansive soils. Therefore, researchers have been trying to investigate the proper measures that could be taken to reduce such expected damages. Soil stabilization is a technique of enhancing the engineering characteristics of soil by increasing its shear strength, durability and reducing settlement, permeability and swelling. Varieties of stabilizers have been used in the stabilization of problematic soils. Several types of research and fieldwork have been conducted with many primitive stabilizers like cement, lime and fly-ash, copper slag, Ground Granulated Blast Furnace etc. ${ }^{1,2}$ Researchers have been trying to propose other non-traditional stabilizers such as ionic stabilizers, enzymes, salts, resins, lignosulphates, tree resins, polymers, acids etc. ${ }^{3-6}$

Traditional stabilizers generally require prolonged curing periods and large quantities for significant strength improvement. Naeini et al. reported that the stabilization of fine-grained clayey soils with aqueous polymer increases the strength behavior and can be possibly beneficial in time and economy as they require a lesser curing period. ${ }^{7}$ However, the method of application, the quantity and curing periods required for non-traditional admixtures cannot be judged unless proper research is done on the suitability to a particular soil type. Jin Liu et. al. explored the effect of polyvinyl acetate on the shrink-swell behavior of clay and reported that there is a decrease in linear shrinkage ratio and linear swelling ratio.

Rasayan J. Chem., 14(2), 1148-1158(2021)

http://dx.doi.org/10.31788/ RJC.2021.1426057

This work is licensed under a CC BY 4.0 license. 
RASĀYAN J. Chem.

Vol. 14 | No. 2 |1148-1158| April - June | 2021

The hydrophile groups $\left(-\mathrm{OOCCH}_{3}\right)$ present in PVA's molecular structure react electrochemically with clay particles and form bonds between clay surfaces and polymer molecules. ${ }^{8}$ Mirzababei et. al. reported that clay samples stabilized with polyvinyl alcohol crosslinked with 1,2,3,4 Butane Tetra Carboxylic acid with a curing period of 1 to 14 days indicated that water-loving polymers enhanced the UCS value of soft clay soil. ${ }^{9}$ Mirzababei et. al. treated expansive soils with 1,3 and 5\% PVA and found a reduction in swelling behavior. ${ }^{10}$ The use of anionic PAM as a stabilizer has been explored by Georgees et al. proving an increase in UCS value, resistance to erosion and abrasion. ${ }^{11}$ Kolay et al. studied the consequences of adding vinyl copolymer liquid stabilizer on high plasticity clay and concluded an increase of about $400 \%$ in unconfined compressive strength. ${ }^{12}$ Lentz testified that PAM showed better results in terms of flocculation and aggregate stability. ${ }^{13}$ Three possible mechanisms: electrostatic interaction, Van der Waals interaction and hydrogen bonding can affect the interaction between soil particles and polyacrylamide. ${ }^{14}$ Soltani et al. investigated the use of PAM and ground rubber for expansive soil stabilization and found that using PAM alone for stabilization caused $127.5 \%$ increase in UCS value at 7 days curing period. ${ }^{15}$ Several factors like the type of polymer used, temperature, the molecular weight of the polymer, method of curing, etc. affect the soil-polymer interaction. ${ }^{16,17}$ Combination of PVA and $\mathrm{K} 2 \mathrm{CO} 3$ is effective in stabilization of expansive soil as it reduces swell and increases UCS value. ${ }^{18}$ The use of polyacrylamide as a soil conditioner, in-furrow irrigation, rain-fed irrigation and in construction to control soil erosion has been discussed by Green et al. and Silva et al. ${ }^{19,20}$

In this study, polyvinyl acetate -a cationic polymer and polyacrylamide -an anionic polymer have been used to study their influence on strength properties of expansive clayey soil through an unconfined compression test.

\section{Soil Sample}

\section{EXPERIMENTAL}

The soil sample required for this study was retrieved from Hubli, Karnataka state of India from a depth of 2-3 meters from the top surface. Various properties tests concluded the soil to be classified as highly plastic clay according to Indian Standard Soil Classification System (ISSCS) with a specific gravity of 2.4. The particle size analysis as shown in Fig.-1 shows clay, silt and sand content of 59\%, 30\% and 11\% respectively. The liquid limit, plastic limit, plasticity index and shrinkage limit of soil sample was obtained as $60 \%$ and $26.45 \% 33.55 \%$ and $6.43 \%$ respectively. The soil has a free swell index of $60 \%$ and is considered as high swelling soil. The maximum dry density $\left(\gamma_{\mathrm{d}, \max }\right)$ and optimum moisture content $\left(\omega_{\text {opt }}\right)$ for the soil sample obtained from the compaction test are $18.25 \%$ and $1.62 \mathrm{~g} / \mathrm{cc}$.

Table-1: Physical Properties of Soil

\begin{tabular}{c|c|c}
\hline Soil Property & Values & Standard Designation \\
\hline Specific Gravity & 2.41 & IS 2720 (III) 1985 \\
\hline Liquid Limit (\%) & 60 & IS 2720 (V) 1985 \\
Plastic Limit (\%) & 26.45 & IS 2720 (V) 1985 \\
Plasticity Index & 33.55 & \\
Shrinkage Limit (\%) & 6.43 & IS 2720 (VI) 1972 \\
Silt Fraction (\%) & 30 & IS 2720 (IV) 1985 \\
Clay Fraction (\%) & 59 & IS 2720 (IV) 1985 \\
Optimum moisture content $\left(\omega_{\mathrm{opt}}\right)(\%)$ & 18.2 & IS 2720 (VII) 1980 \\
\hline Maximum Dry Density $\left(\gamma_{\mathrm{d}, \max }\right)(\mathrm{g} / \mathrm{cc})$ & 1.62 & IS 2720 (VII) 1980 \\
Free Swell Index (FSI) & 60 & IS 2720 (XL) 1977 \\
Soil Classification & $\mathrm{CH}$ & ISSCS \\
\hline
\end{tabular}

\section{Cationic Polymer (Polyvinyl Acetate Emulsion, PVA)}

Polyvinyl acetate (PVA) is a water-soluble and viscous polymer prepared by the polymerization of vinyl acetate $(\mathrm{CH} 3 \mathrm{COOCH}=\mathrm{CH} 2)$. Because of its excellent adhesion and convenience, it is widely used as an 
RASĀYAN J. Chem.

Vol. 14 | No. 2 |1148-1158| April - June | 2021

adhesive for paper and woodwork. It has been used by many researchers to enhance the properties of clayey soils. PVA procured from Monichem Adhesives Private Limited, Chennai, Tamil Nadu has properties tabulated in Table-2.

\section{Anionic Polymer (Polyacrylamide, PAM)}

Polyacrylamide is a polymer $(-\mathrm{CH} 2=\mathrm{CHCONH} 2-)$ formed from acrylamide subunits. It is an organic water-soluble polymer having high molecular weight derived from petroleum which can form a long molecular chain. Anions or cations in soil or water facilitate the formation of bridges with soil particles. Since anionic PAM has a negative charge as in clay surface, it would be predicted to encounter repulsive forces from the clay surfaces having negative charges. However, a mechanism called cation bridging binds the negative sites. The anions, either of the clay surface or the anionic PAM, tie up with each cation of a divalent cation. The largest use of PAM is to flocculate solids in a liquid. The anionic form of PAM is used as a soil conditioner on agricultural land and for erosion control on construction sites. ${ }^{19,20}$ PAM increases pore spaces in soil containing clay, increases water infiltration and prevents soil crusting. The properties of anionic polyacrylamide supplied by Acuro Organics Ltd, India are tabulated in Table-3.
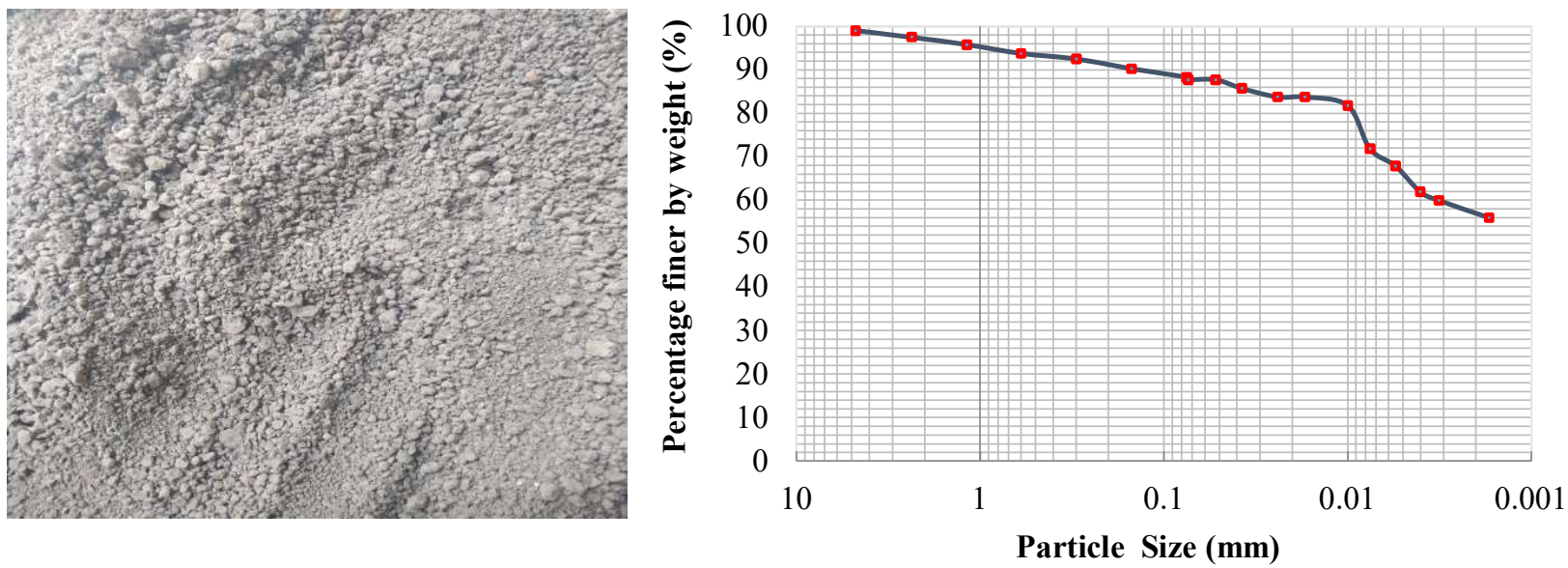

Fig.-1:(a) Collected Soil; (b) Particle Grain Size Distribution of Soil Sample
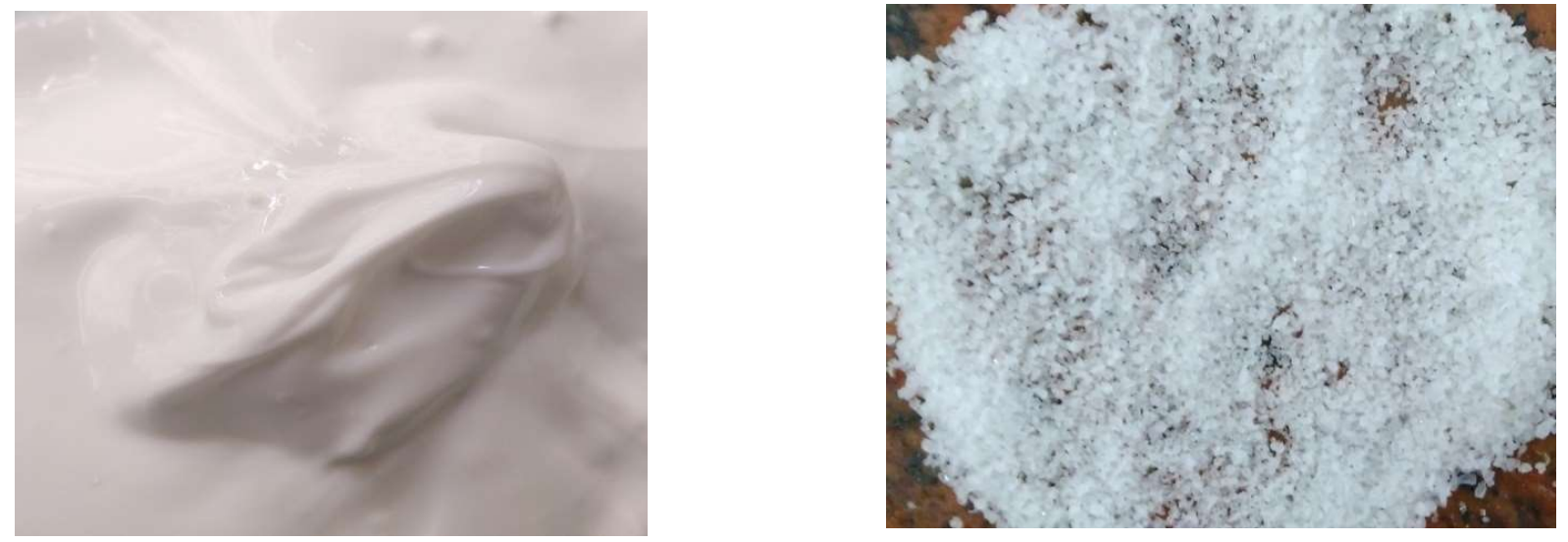

Fig.-2: (a) PVA, (b) PAM Granules 
RASĀYAN J. Chem.

Vol. 14 | No. 2 |1148-1158| April - June | 2021

Table-2: Properties of Polyvinyl Acetate

\begin{tabular}{c|c}
\hline Properties & Values \\
\hline Physical state & Milky White \\
Solubility & Soluble in Water \\
Total Solids (\% by weight) & $42 \%$ \\
Viscosity & $400 \mathrm{mPoise}$ \\
\hline
\end{tabular}

Table-3: Properties of Polyacrylamide

\begin{tabular}{c|c}
\hline Properties & Values \\
\hline Physical state & White Granules \\
Ionicity & Medium Anionic \\
Bulk Density $(\mathrm{kg} / \mathrm{m} 3)$ & 0.7 \\
Effective $\mathrm{pH}$ range & $5-12$ \\
Aqueous Solution $\mathrm{pH}$ & $6-8$ \\
Molecular Weight $\left(\mathrm{x} 10^{4}\right)$ & 1900 \\
\hline
\end{tabular}

\section{Experimental Program}

The soil sample was firstly sun-dried, pulverized and mixed thoroughly to ensure homogeneity in the properties of all the tests. Standard Proctor test was firstly conducted with $1 \%, 2 \%, 3 \%$ and $4 \%$ polymer content by weight for both PVA and PAM. It was detected that with an increase in polymer content, the $\omega_{\mathrm{opt}}$ increased and $\gamma_{\mathrm{d}, \max }$ decreased. A trial compressive strength (UCS) test was conducted on soil samples for all the above-mentioned proportions. There was a huge reduction in UCS value for polymer content more than $2 \%$ by dry weight. Hence, proportions of $0.5 \%, 1 \%, 1.5 \%$ and $2 \%$ polymer content were fixed for the experimental program in this study.

Unconfined compressive strength test samples of height $=76 \mathrm{~mm}$ and diameter $=38 \mathrm{~mm}$ were cast through static compaction on a split mold sampler. The samples were compacted at the mean value of $\omega_{\text {opt }}$ and $\gamma_{\mathrm{d}}$, max resulted from the compaction test for $0 \%, 1 \%$ and $2 \%$ polymer content. The samples hence prepared were preserved inside zip lock bags and were kept for curing on the wet sand bed and covered by a wet jute bag. The curing periods selected for the study were $0,3,7$ and 14 days. The samples were tested on a UCC tester at a uniform displacement rate of $1.25 \mathrm{~mm} / \mathrm{min}$ till the samples failed.

The optimum proportion of polymer that yielded the highest UCS value and one another proportion of polymer was used for the determination of oedometric swell potential and swell pressure. The specimens were prepared on oedometer ring of $60 \mathrm{~mm}$ diameter and $20 \mathrm{~mm}$ height at $10 \%$ moisture content. The compacted soil specimens were cured as did for UCS test samples. The curing periods selected for this study were 3 days and 7 days. The soil sample was placed in oedometer, inundated with water and dial gauge readings were recorded to obtain the swell potential value. After maximum swelling of the sample had occurred, loads were applied on the swollen sample to bring it back to the original volume. The pressure required to bring back the swollen sample to the original height/volume is taken as the swelling pressure of the soil sample.

Field Emission Scanning Electron Microscope (FESEM) was utilized to study the microstructure of virgin soil and soil treated with polymers. SEM imaging was conducted in FEI, Quanta 200 Scanning Electron Microscope.

\section{RESULTS AND DISCUSSION}

\section{Effect on Compaction Characteristics}

The standard proctor test result for various proportions of PVA and PAM is shown in Fig.-3. It can be seen that optimum moisture content (OMC) is increased and the maximum dry density (MDD) is diminished on increasing polymer content for both polymers. In addition to $2 \%$ PVA emulsion, dry density value reduced from $1.62 \mathrm{~g} / \mathrm{cc}$ to $1.59 \mathrm{~g} / \mathrm{cc}$ and optimum water content escalated from $18.25 \%$ to 
RASĀYAN J. Chem.

Vol. 14 | No. 2 |1148-1158| April - June | 2021

$20.8 \%$. Similarly, on addition $2 \%$ PAM by dry weight of soil, the MDD lowered from $1.62 \mathrm{~g} / \mathrm{cc}$ to 1.57 $\mathrm{g} / \mathrm{cc}$ and $\mathrm{OMC}$ increased from $18.25 \%$ to $20.6 \%$. The PVA emulsion is in an aqueous form which contributes to an increase in OMC. Similarly, PAM, being a hydrogel polymer having long molecule chains capture water molecules and soaks up water ${ }^{20}$ and hence OMC increases.

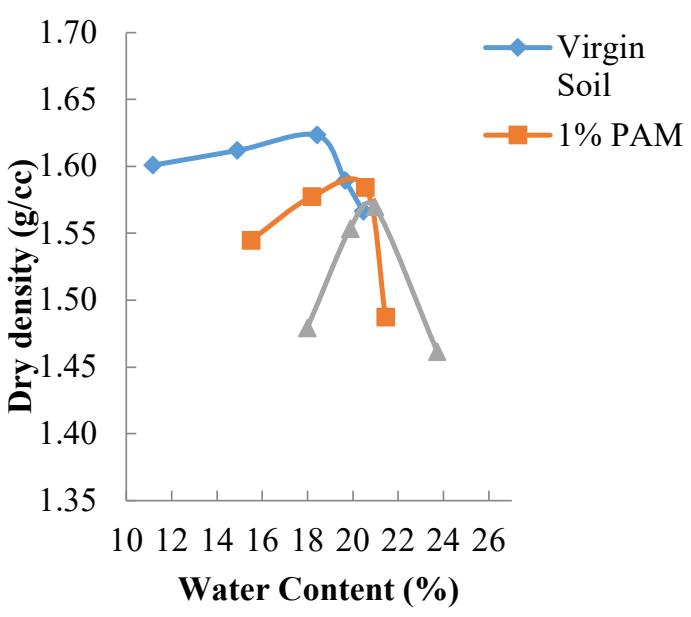

a

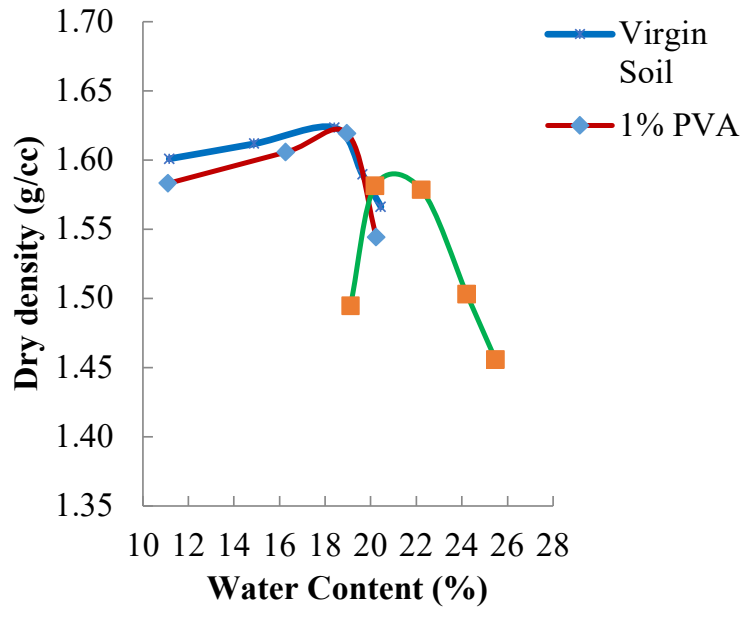

$\mathrm{b}$

Fig.-3: Standard Proctor Compaction Curve for (a) Soil treated with PAM, (b) Soil treated with PVA

\section{Effect on Unconfined Compressive Strength (UCS)}

Figure-4 and Fig.-5 show the stress-strain curves for various proportions of PVA and PAM respectively. The compressive strength of virgin soil was obtained as $196.96 \mathrm{kPa}$. For PVA used as an admixture, there was not much difference in the UCS value obtained for various proportions for samples cast and tested on the same day ( 0 days curing). For $0.5 \%$ PVA addition, the UCS increased to $200.5 \mathrm{kPa}, 220.94 \mathrm{kPA}$ and $256.14 \mathrm{kPa}$ for 3, 7 and 14 days curing period. The maximum increase in strength was visualized for the addition of 1\% PVA which yielded $314.59 \mathrm{kPa}, 332.8 \mathrm{kPa}$ and $355.86 \mathrm{kPa}$ for curing periods of 3,7 and 14 days respectively. On further increasing the polymer content, the strength was reduced. This might be due to the reasons that the pore filling and binding of soil particles occurred at $1 \%$ PVA content and on further increasing PVA content, the admixture acted as a lubricant and facilitated particle sliding and failure.

For PAM used as a stabilizer, there was a slight increase in the UCS value. For samples cast and tested on the same day, there was a rise in strength of about $20 \%$ for soil treated with $1 \%$ PAM. For PAM content of $0.5 \%$, the strength increased to $327.83 \mathrm{kPa}$ for 3 days curing and to $357.9 \mathrm{kPa}$ under 7 days curing. But, on increasing the curing period, strength produced by soil treated with $0.5 \%$ PAM decreased. For PAM content of $1 \%$, the strength increased to $303.93 \mathrm{kPa}$ and $332.64 \mathrm{kPa}$ under 3 days and 7 days curing period. On further increasing the PAM content, the compressive strength dropped. Fig.-6 shows the variation in compressive strength of treated soil under various curing periods. From the stress-strain graphs, the strain energy of the polymer-treated soil samples reduced. It may be because pore water is utilized by polymers for polymerization action and formed a stiff soil matrix causing the soil to be brittle.

\section{Influence on Swell Behavior}

Figure-7 shows the swell potential of soil samples treated with 1\% and 2\% PVA and cured for 3 and 7 days. The swell potential of soil treated with 1\% PVA and cured for 3 and 7 days showed an increase in swell potential with values of $5.9 \%$ and $6.08 \%$ respectively. But, on increasing the PVA content to $2 \%$, there was not much significant difference in the value of swell potential in comparison to the swell potential of virgin soil sample. 
RASĀYAN J. Chem.

Vol. 14 | No. 2 |1148-1158| April - June | 2021

Flocculation of soil was higher at 1\% PVA content compared to 2\% PVA content and hence swell potential was more for $1 \%$ PVA treated soil.

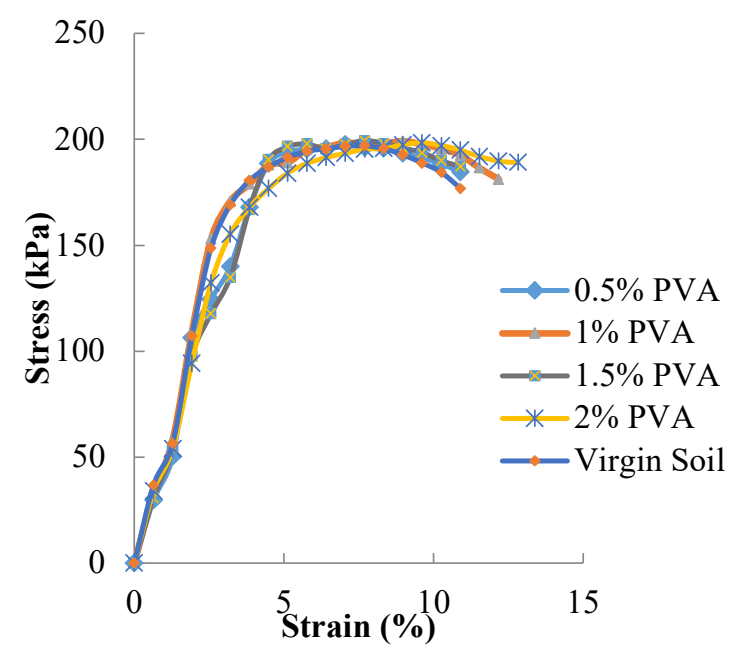

$\mathrm{a}$

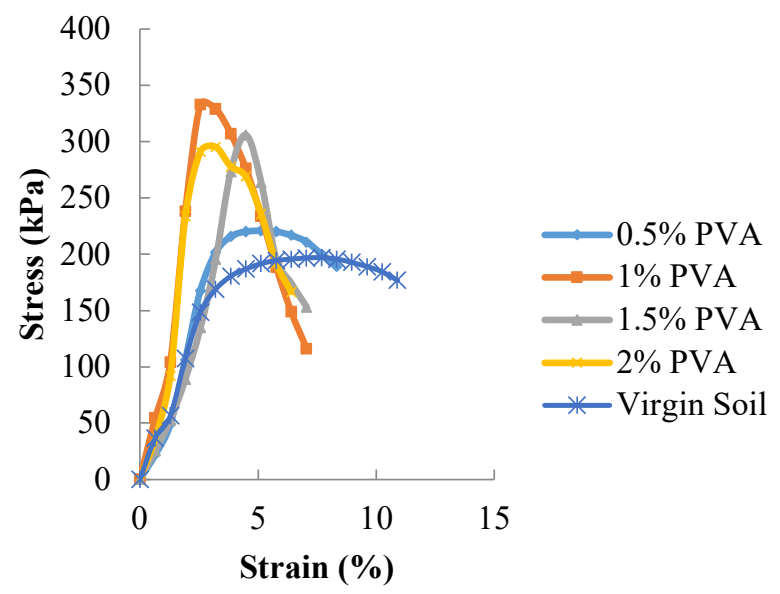

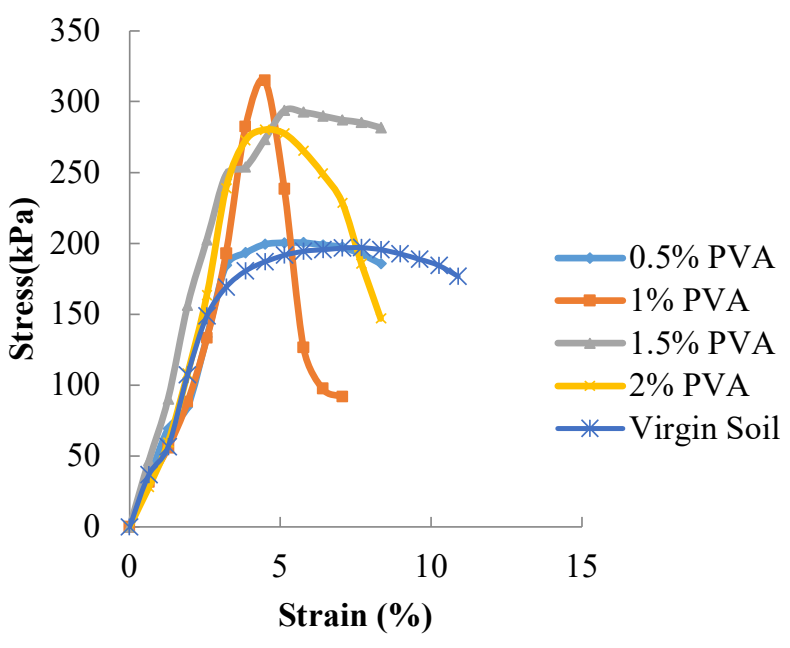

b

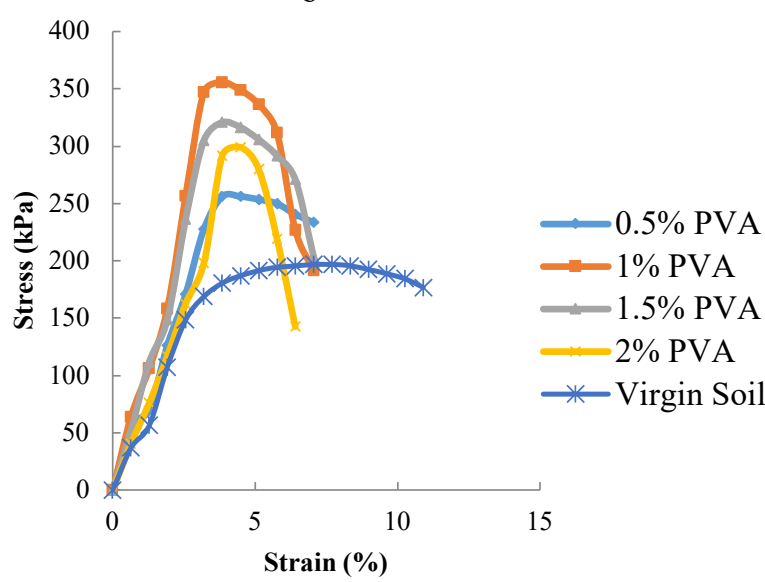

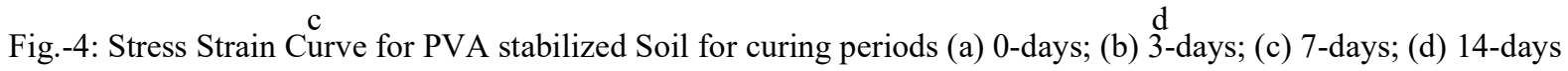

Figure-8 illustrates the swell potential test results conducted on samples treated with $0.5 \%$ and $1 \%$ PAM content under 3 (3D) and 7 days (7D) curing periods. The figure depicts that the swell potential increased with the addition of PAM on the soil sample. The swell potential value reached the maximum of $7 \%$ for $0.5 \%$ PAM treated soil when cured for 3 days and a similar value of $6.69 \%$ was observed for $1 \%$ PAM treated soil cured for 3 days. The swell potential obtained for $0.5 \%$ PAM treated soil when cured for 7 days is $5.64 \%$ and for $1 \%$ PAM treated soil cured for 7 days is $5.7 \%$.

Figure- 9(a) and (b) illustrate the results of swell pressure tests on samples treated with $1 \%$ and $2 \%$ PVA and cured for 3 (3D) and 7 days (7D) respectively. With the addition of PVA, although the swell potential had increased, the swell pressure decreased. The rise in swell potential value is because of the formation of flocculated structure at 1\% PVA content but the flocculated particles settled at lower oedometric load back values which resulted in a decrease in swell pressure. On changing the curing period, no significant influence was visualized on both swelling potential and swelling pressure values. 
RASĀYAN J. Chem.

Vol. 14 | No. 2 |1148-1158| April - June | 2021

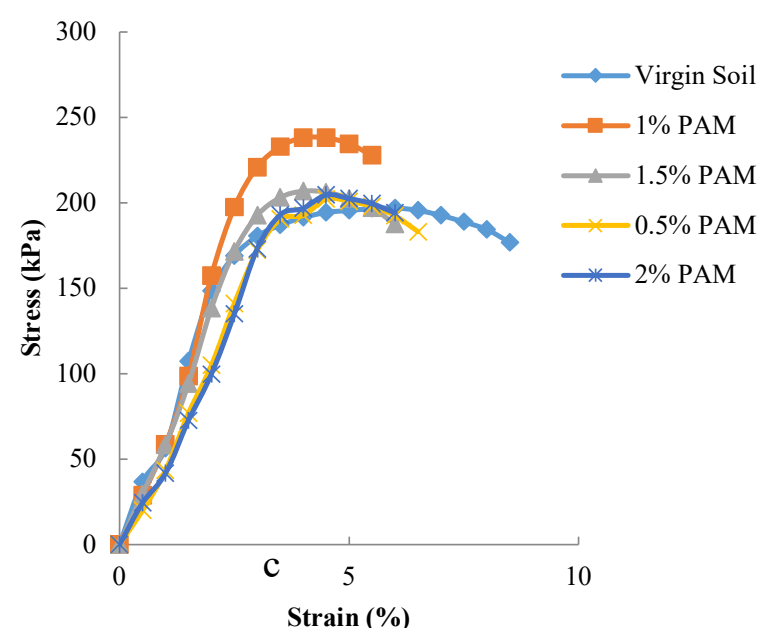

a

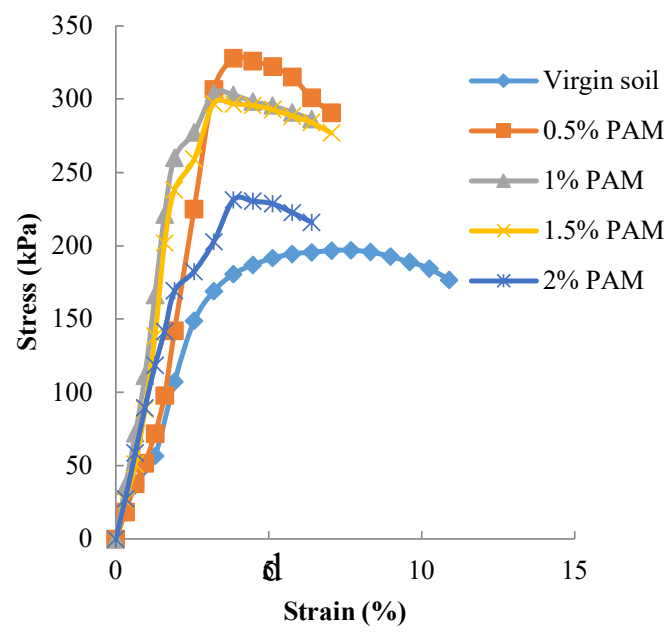

$\mathrm{b}$
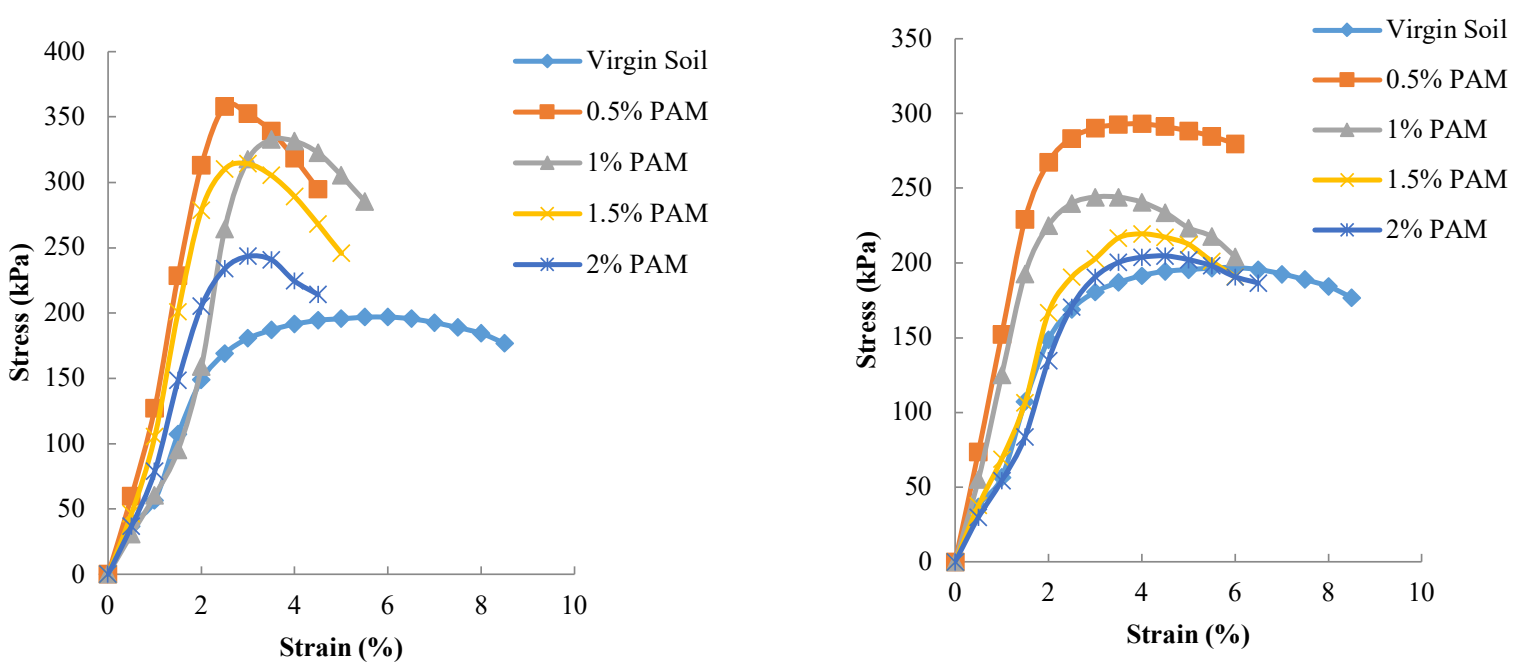

c

d

Fig.-5: Stress Strain Curve for PAM stabilized Soil for curing periods (a) 0-days; (b) 3-days; (c) 7-days; (d) 14-days

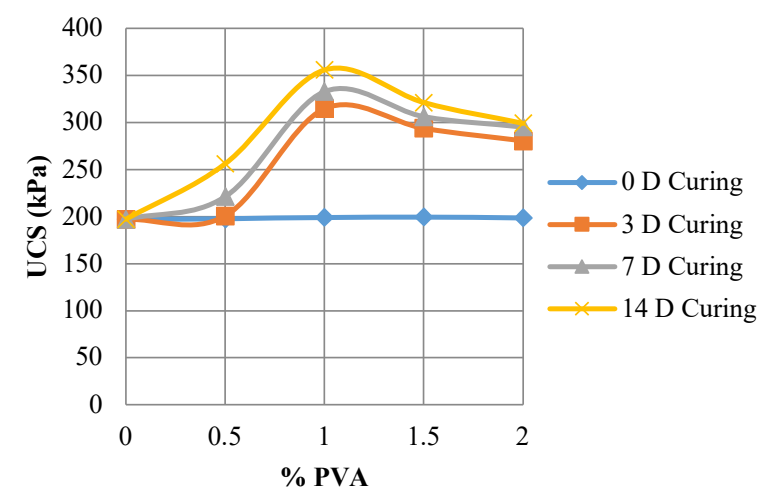

a

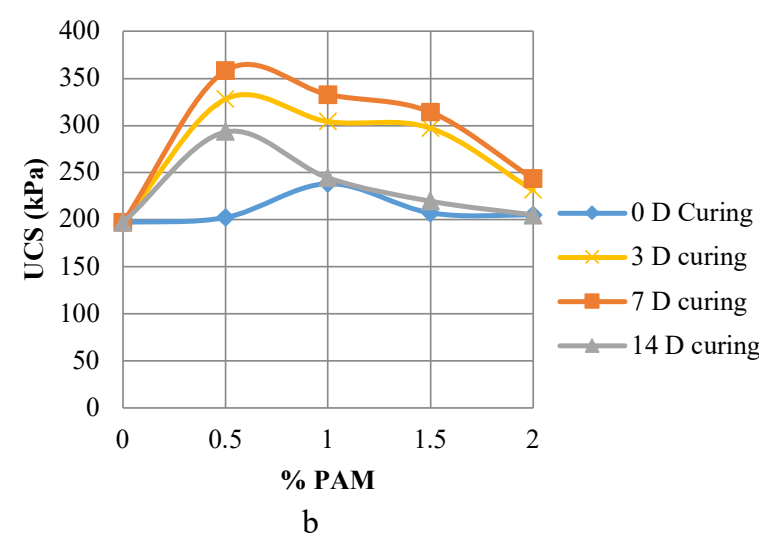

b

Fig.-6: Effect of Polymer Content on UCS of Soil for Various Curing Periods 
RASĀYAN J. Chem.

Vol. 14 | No. 2 |1148-1158| April - June | 2021
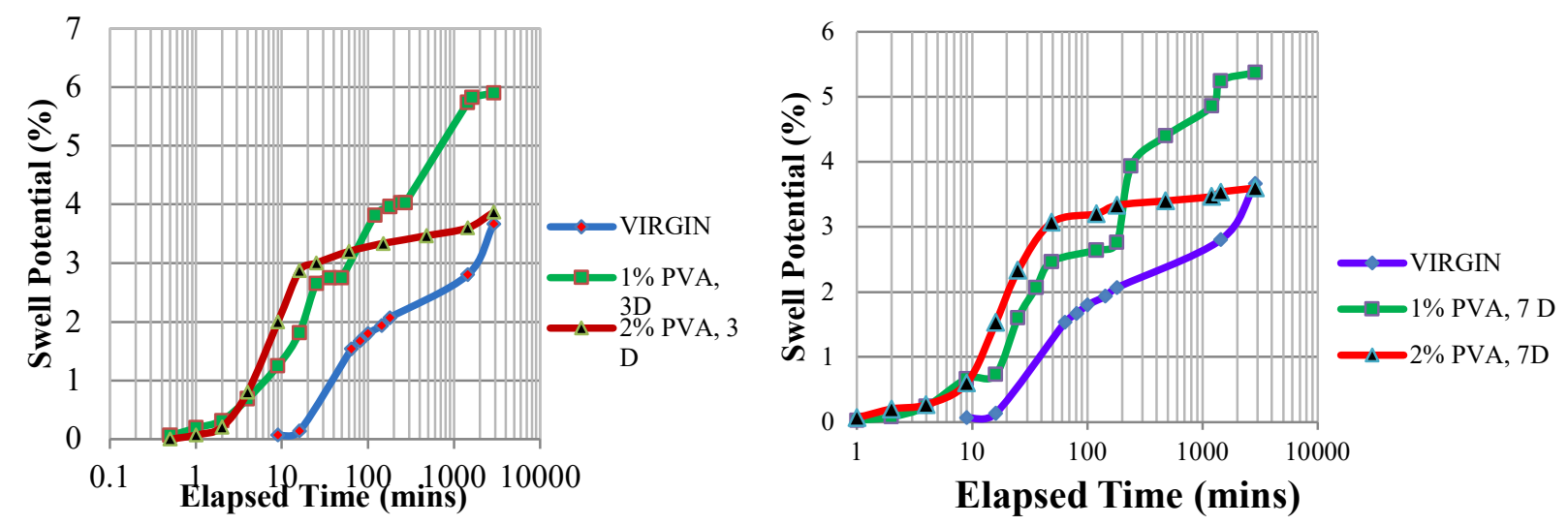

Fig.-7: Swell Potential Test on Samples treated with 1\% and 2\% PVA Content under (a) 3 days (3D) curing period and (b) 7 days (7D) curing period.
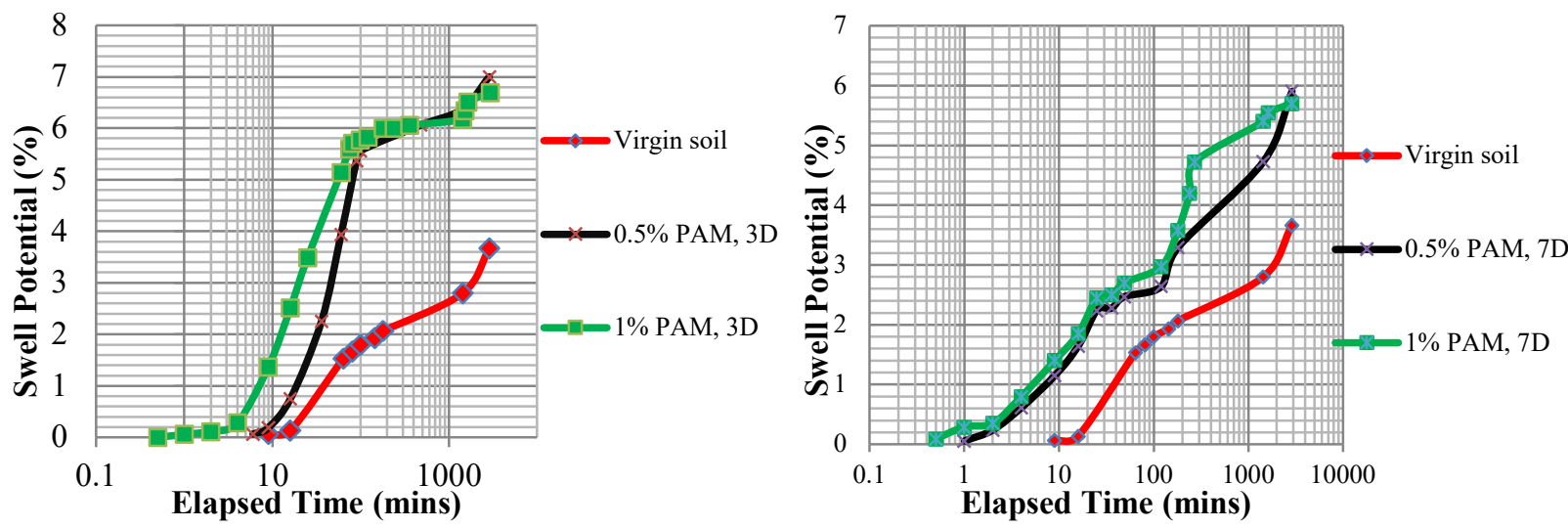

Fig.-8: Swell Potential Test on Samples treated with $0.5 \%$ and $1 \%$ PAM Content under (a) 3 days (3D) and (b) 7 days (7D) curing periods.
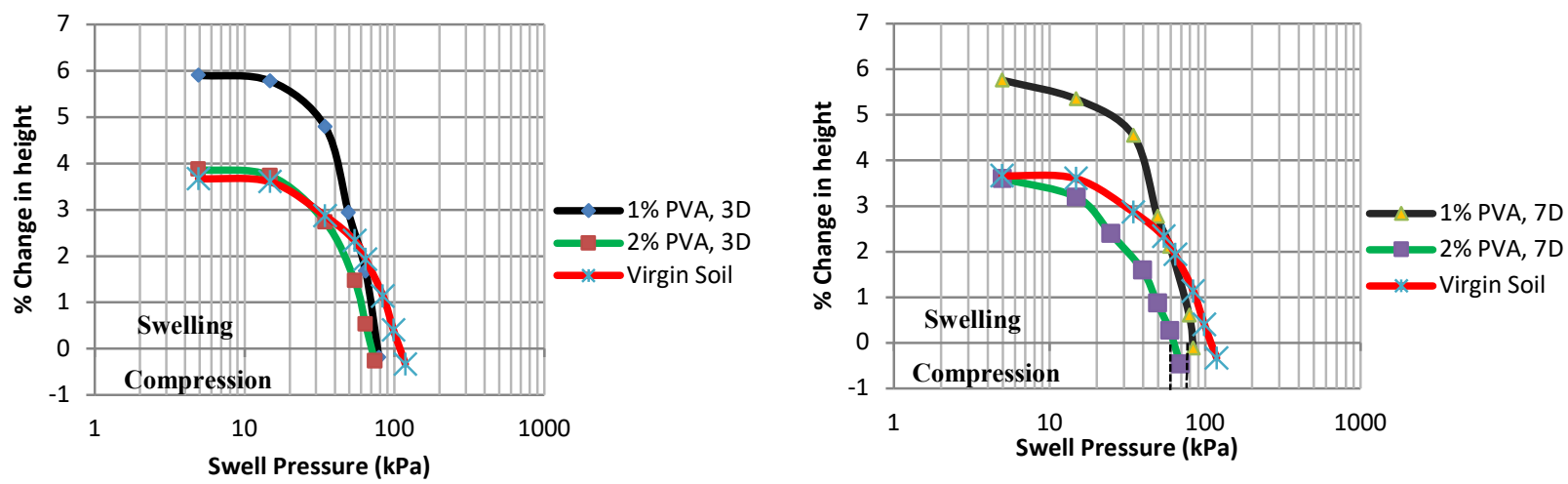

Fig.-9: Swell Pressure Test on Samples treated with 1\% and 2\% PVA Content under (a) 3 days (3D) and (b) 7 days (7D) curing periods

Figures-10(a) and (b) illustrates the results of swell pressure tests on samples treated with $0.5 \%$ and $1 \%$ PAM and cured for 3 (3D) and 7 days (7D) respectively. With the addition of PAM, although the swell potential had increased, the swell pressure of treated soil decreased. The increase in swell potential is because of the formation of dispersed structure when soil is treated with PAM but the dispersed particles 
RASĀYAN J. Chem.

Vol. 14 | No. 2 |1148-1158| April - June | 2021

settled at lower oedometric load back values which resulted in a decrease in swell pressure. On changing the curing period, no significant influence was visualized on both swelling potential and swelling pressure values.
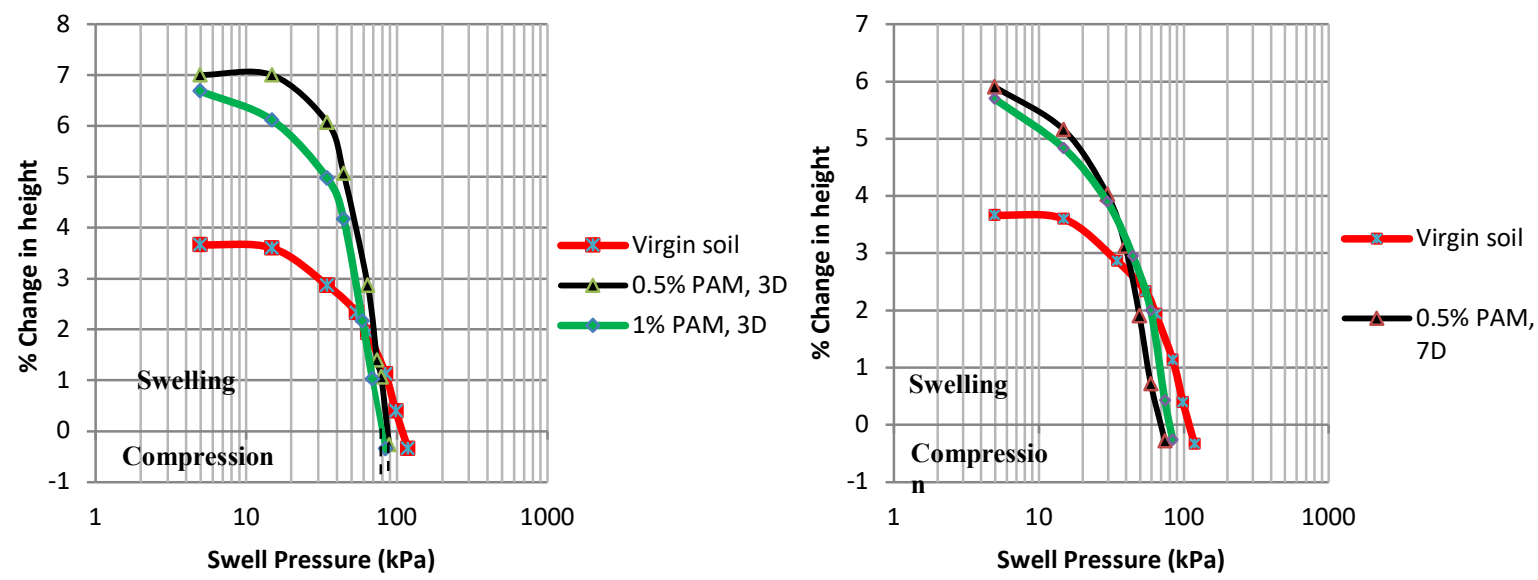

Fig.-10: Swell Pressure Test on Samples treated with 0.5\% and 1\% PAM Content under (a) 3 days (3D) and (b) 7

\section{SEM Analysis}

days (7D) curing periods

The optimum proportion of polymers yielding the highest value of unconfined compressive strength were taken for this analysis. Fig.-11 shows the SEM images of virgin soil sample and soil treated with PVA and PAM under magnification of 2500x and 20,000x. The microstructure of natural soil as seen in the figure shows partly dense particles with large voids in-between. However, in the polymer-stabilized soil samples, the dense and homogeneous matrix can be visualized which proves that the increase in strength is through particle aggregation and flocculation.
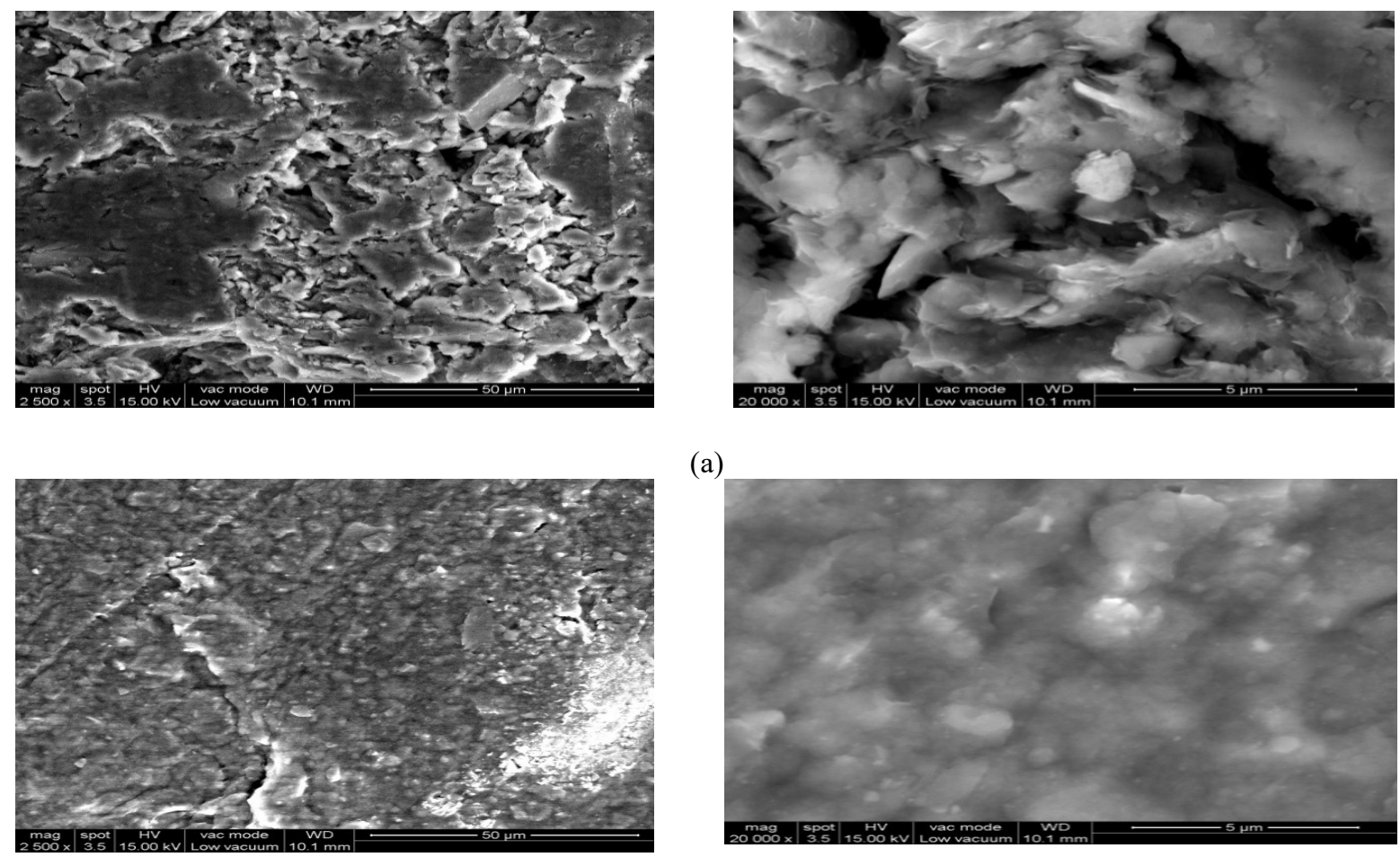

(a)

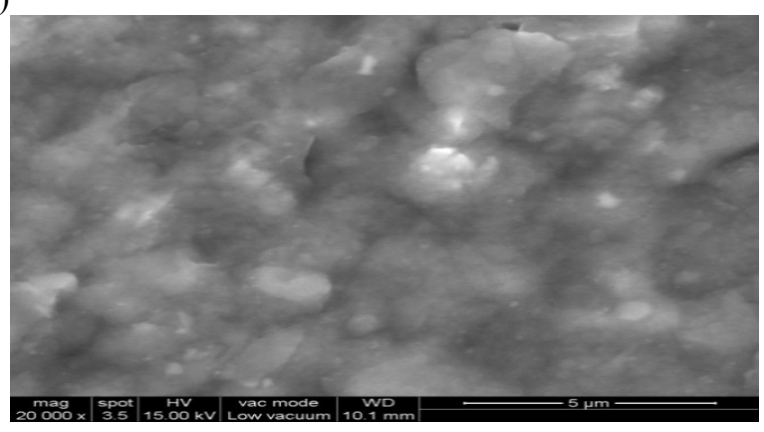

(b) 

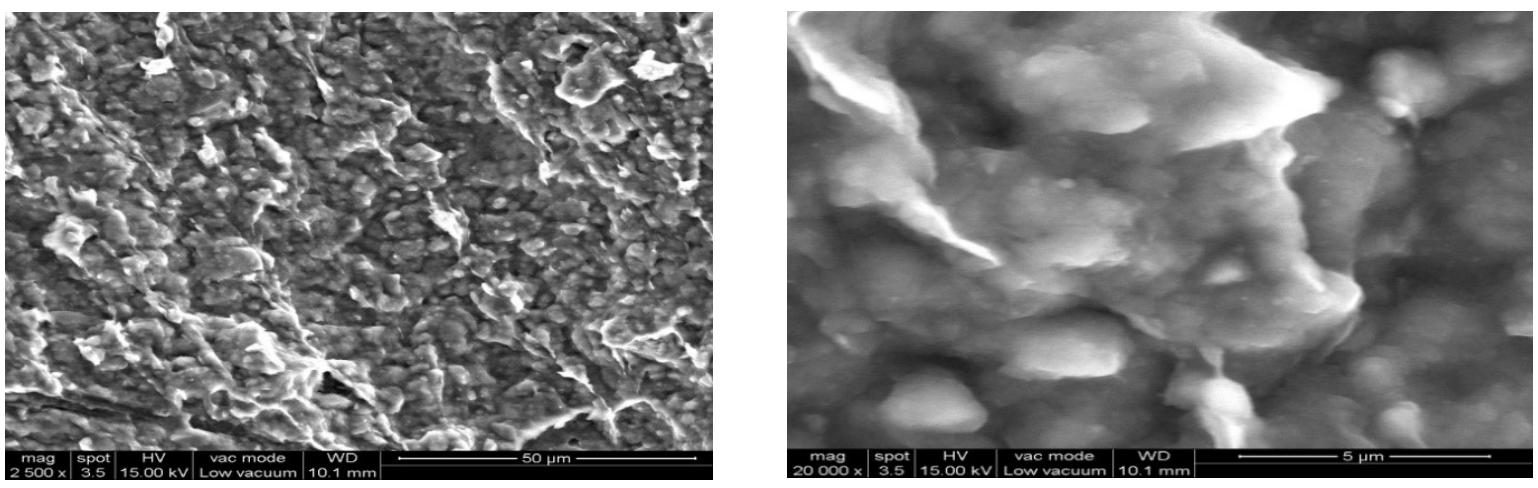

(c)

Fig.-11: SEM Images with 2500x and 20,000x magnification of (a) Virgin Soil, (b) 1\% PVA treated Soil, (c) $0.5 \%$ PAM treated Soil

\section{CONCLUSION}

This research study summarizes the influence in strength and swelling behavior of expansive clay soil when treated with cationic (PVA) and anionic (PAM) polymers. Compaction characteristics test, unconfined compression test, swell tests and SEM analysis were conducted to assess the changes that occurred. The following interpretations can be made from the present study:

- The maximum dry density decreased and optimum moisture content increased for soil treated with both cationic PVA and anionic PAM. Polymers take extra water for polymerization action and the polymers had lower specific gravity causing a decrease in dry density.

- The increase in UCS value was seen to improve on increasing polymer content up to a certain proportion i.e. $1 \%$ for PVA and $0.5 \%$ for PAM. A higher concentration of polymer caused soil particles to slide among particles rather than causing flocculation and hence decreased the UCS value.

- The increase in strength for PVA-treated soil was seen until 14 days curing but for PAM stabilized soil, the UCS value increased till 7 days curing and then started to decrease.

- The swell potential of soil treated with optimum content of polymers yielding the highest UCS value is higher than that of virgin soil sample. However, swell pressure was reduced than that of untreated soil. Although there is an increase in the swell potential of treated soil, upon application of load, the flocculated structure broke and particles reoriented easily at lesser loads than for virgin soil sample and hence swelling pressure reduced. No significant effect of curing period on swell behavior when treated with polymers.

- The SEM image analysis illustrated that a homogeneous and dense soil matrix is formed when natural soil is treated with polymers causing an increase in strength.

\section{REFERENCES}

1. Zhang Ji-ru and Cao Xing, Journal of Wuhan University of Technology-Material Science Ed.,17, 73(2002), DOI: 10.1007/BF02838423

2. M.Kavisri, P. Senthilkumar, M.S Gurukumar and Karunian J. Pushparaj, Rasayan Journal of Chemistry, 11(1), 111(2018), DOI:10.7324/RJC.2018.1111805

3. J. S. Tingle, J. K. Newman, S. L. Larson, C. A. Weiss, J. F. Rushing, Transportation Research Record: Journal of the Transportation Research Board, 1989-2(1), 59(2007), DOI:10.3141/1989-49

4. Rosa L. Santoni, Jeb S. Tingle and Steve L. Webster, Transportation Research Record: Journal of the Transportation Research Board, 1787 (1), 61(2002), DOI:10.3141/1787-07

5. S.Janaki Raman, P.D. Arumairaj, R. Tikson Sebastian, J. Jerushan, D. Jeabraj Samuel Dorai and Nathaniel Joseph Thomas, Rasayan Journal of Chemistry, 11(4), 1729(2018), DOI: $10.31788 /$ RJC.2018.1143089 
RASĀYAN J. Chem.

Vol. 14 | No. 2 |1148-1158| April - June | 2021

6. Mohanned Waheed and Noor Asmael, MATEC Web of Conferences, 162, 01027(2018), DOI:10.1051/matecconf/201816201027

7. Sayed Abolhassan Naeini, Bahman Naderinia, Ehsan Izadi, KSCE Journal of Civil Engineering 16(6), 943(2012), DOI:10.1007/s12205-012-1388-9

8. Jin Liu, Yong Wang, Yi Lu, Qioa Feng, Faming Zhang, Changqing Qi, Jihong Wei, Debi Prasanna Kanugo, International Journal of Polymer Science, 2017, 8128020(2017), DOI: $10.1155 / 2017 / 8128020$

9. M. Marzababaei, A. Arulrajah, M. Ouston, Transportation Geotechnics and Geoecology, TGG 2017, Procedia Engineering 189, 25(2017), DOI:10.1016/j.proeng.2017.05.005

10. M. Marzababaei, Seyyed Shahaboddin Yasrobi, Amer Ali Al-Rawas, Proceedings of the Institution of Civil Engineers, Ground Improvement, 162(3), 11 (2009), DOI:10.1680/grim.2009.162.3.111

11. Romel N. Georgees, Rayya A. Hassan, Robert P. Evans, Piratheepan Jegatheesan, Construction and Building Materials, 148, 686(2017), DOI:10.1016/j.conbuildmat.2017.05.086

12. Prabir K. Kolay, Basanta Dhakal, Sanjeev Kumar, Vijay K. Puri, International Journal of Geosynthetics and Ground Engineering, 2, 29(2016), DOI:10.1007/s40891-016-0071-5

13. R.D. Lentz, Geoderma, 241-242, 289 (2015), DOI:10.1016/j.geoderma.2014.11.019

14. William J. Orts, Aicardo Roa Espinosa, Robert E. Sojka, Gregory M. Glenn, Syed H. Imam, Kurt Erlacher, and Jan Skov Pederson, Journal of Materials in Civil Engineering, 19(1), 58(2007), DOI: 10.1061/(ASCE)0899-1561 (2007)19:1(58)

15. Amin Soltani, An Deng, Abbas Taheri and Brendan C. O’Kelly, Polymers 11, 1675(2019), DOI: $10.3390 /$ polym 11101675

16. Sepehr Rezaeimalek, Abdolreza Nasouri, Jie Huang, Sazzad Bin-Shafique, Simon T. Gilazghi, Journal of Traffic and Transportation Engineering, 4(2), 145(2017), DOI:10.1016/j.jtte.2017.01.003

17. B.K.G Theng, Clay and Clay Minerals, 30(1), 1(1982)

18. Fuhai Zhang, Lei Zhang and Wangxi Hong, Advances in Civil Engineering, 2019, 7032087(2019), DOI: $10.1155 / 2019 / 7032087$

19. V. Stevan Green and D.E Stott, 2001, Polyacrylamide: A review of the use, effectiveness, and cost of a soil erosion control amendment, in: D.E Stott, R.H Mohtar and G.C Stein Hardt (eds), Sustaining the Global Farm, pp-384-389.

20. Alexandre Marco da Silva, Steven F. Durrant, Jounal of Sustainable Development, 3(4), 109(2010), DOI: $10.5539 /$ jsd.v3n4p109

[RJC-6057/2020] 